\title{
Bayley Scale of Infant Development II
}

National Cancer Institute

\section{Source}

National Cancer Institute. Bayley Scale of Infant Development II. NCI Thesaurus. Code C99149.

The second edition of the Bayley Scales of Infant Development, a standardized series of measurements that assesses the cognitive, motor, and behavioral development in infants and babies from one to twenty-four months of age. 